\title{
Pobreza, violência e trabalho: a produção de sentidos de meninos e meninas de uma favela ${ }^{1}$
}

\author{
Neuza Maria de Fátima Guareschi \\ Fernanda Pacheco de Oliveira \\ Letícia Goldenberg Giannechini \\ Luciele Nardi Comunello \\ Milena Nardini \\ Milena Leal Pacheco \\ Pontifícia Universidade Católica do Rio Grande do Sul
}

\begin{abstract}
Resumo
Este artigo se propõe a discutir os sentidos que são produzidos em relação à pobreza, à violência e ao trabalho. Considerando as condições sociais, econômicas, culturais e políticas de exclusão de onde vivem, procurou-se compreender como os sentidos produzidos interpelam meninos e meninas na construção das identidades de gênero, raça, classe social e sexo, nos espaços da casa, da rua, da escola e da comunidade. Para isso, foram realizados 6 grupos de discussão e 16 entrevistas individuais com meninos e meninas, entre 15 e 18 anos, de uma $5^{\mathrm{a}}$ e uma $8^{\mathrm{a}}$ séries do Ensino Fundamental de uma escola municipal da zona leste de Porto Alegre, de uma comunidade carente. A análise e compreensão desses sentidos foram construídos a partir dos pressupostos teóricos e metodológicos da Produção de Sentidos, dentro do paradigma do Construcionismo Social. A pobreza produz um sofrimento e, esses são aspectos que fazem parte da vida desses jovens. A violência é tratada com uma certa naturalidade, mas ao mesmo tempo com uma preocupação, além de ser localizada geograficamente. Já o trabalho é usado como critério para identificar e caracterizar quem mora na favela, especificando, os que trabalham como pessoas honestas, e os que não trabalham como marginais ou bandidos.
\end{abstract}

Palavras-Chave: produção de sentidos, identidades/diferenças, realidade social

\begin{abstract}
Poverty, violence and work: the boy's and girl's meaning production in a poor community. This article aims to discuss the production of meanings about poverty, violence and work. According to the social, economic and cultural conditions, this work analyzes the intersections of gender, racial, social class and sexual girl's and boy's identities construction in the community spaces such as the street, the school and the home. Sixteen interviews and six discussion groups were carried out with girls and boys, between fifteen and eighteen years old, from fifth and eight grade in school. The understanding of the meanings of these girls and boys was based on theoretical and methodological social constructionism approach. The meaning of poverty is perceived by these girls and boys as burden. The violence is taken as concerning, but also as something natural. Work is used as a criterion to classify people, differentiating honest persons from delinquents, who do not work.
\end{abstract}

Key-words: meaning production, identities/differences, social reality.

\section{Introdução}

$\mathrm{E}$ ste artigo apresenta-se como parte de uma pesquisa maior, que teve como objetivo investigar o processo de construção das identidades de meninos e meninas entre 15 e 18 anos, de uma 5 $5^{\underline{a}}$ e uma $8^{\underline{a}}$ série do Ensino Fundamental de uma escola municipal da zona leste de Porto Alegre, localizada em uma comunidade de periferia. Considerando as práticas cotidianas desses adolescentes, procurou-se compreender como estes constróem suas identidades a partir dos sentidos que são produzidos em seu cotidiano, nas relações que estabelecem, através das diferenças que os constituem.

O processo de construção das identidades se dá nos espaços da família, da escola, da rua e da comunidade onde vivem, entre outros, os quais são constantemente atravessados por questões ligadas à pobreza, à violência e ao trabalho, 
questões essas que tomam forma, ganham visibilidade através das práticas cotidianas e são objetivadas de diferentes modos em diferentes momentos e contextos. Através de suas relações de gênero, raça, classe social e sexo, buscou-se problematizar a construção dessas identidades através da luta e resistência que travam em busca do reconhecimento das diferenças e das possibilidades de transformação de sentidos hegemônicos. Neste artigo, daremos atenção especial a aspectos relacionados às questões raciais.

Assim, esse estudo, que situa-se no Campo dos Estudos Culturais $^{2}$, busca demonstrar o quanto esses e essas jovens são interpelados por sentidos construídos em seu cotidiano, que se intercruzam constantemente no processo de construção de identidades e produção de subjetividades. Para a compreensão desses temas, foram utilizados aspectos teóricometodológicos dos Estudos Culturais, a partir da discussão que esse campo de estudo realiza dos conceitos de cultura, de identidades, de Produção de Sentidos ${ }^{3}$ e das Políticas de Identidade. Estes referenciais apontam para a necessidade de se deslocar a idéia de cultura do âmbito da reprodução para uma posição onde a ação social é considerada de suma importância, visto que o poder é compreendido como força constitutiva de todo o tecido social, ação sobre outras ações possíveis. Por esta razão, o objeto de estudo do ponto de vista dessa perspectiva se concentra no espaço popular das práticas da vida cotidiana, como no caso deste estudo, relacionando-as com as relações de poder, as lutas políticas e a construção de identidades.

\section{Estudos Culturais: cultura, identidades $e$ diferenças}

Esse trabalho tem seu suporte teórico-epistemológico fundamentado no debate que estamos realizando entre a compreensão de alguns autores (Hall, 1990; Silva, 2000), do campo dos Estudos Culturais, sobre identidades e diferença e de como a Psicologia Social pode rediscutir suas formulações teóricas em relação a esse tema. É importante ressaltar que, embora determinados conceitos e compreensões sejam característicos dos Estudos Culturais, são também utilizados por outras perspectivas, por outros campos. Temos como exemplo disso a ampliação do conceito de cultura, o abandono de posturas etnocêntricas, bem como a compreensão de tudo em seu contexto.

Nelson (1995) afirma que, apesar dos Estudos Culturais rejeitarem uma espécie de definição, podemos nos arriscar em oferecer uma que seja muito geral e genérica. Isto ajudaria a mapear a diversidade de posições e tradições que podem, legitimamente, reivindicar seu nome. Para o autor, esta escola se constitui de um campo interdisciplinar, transdisciplinar e algumas vezes contra-disciplinar. Dessa forma, se utilizam de todas as disciplinas que forem necessárias para produzir o conhecimento exigido por um projeto particular. Por isso, Johnson (1986) define essa escola como uma alquimia para produzir conhecimento útil sobre a cultura humana, que propõe o uso de um referencial teórico de análise e compreensão do objeto de estudo a partir de diferentes disciplinas.
A cultura é um dos operadores conceituais mais importantes para os Estudos Culturais, por se apresentar tanto em um sentido "substantivo", ao se localizar na estrutura empírica e na organização das ações, instituições, relações sociais, quanto em um sentido "epistemológico", por transformar as formas de conhecimento e conceitualizações que modificam a própria experiência do real. Tal concepção de cultura surge no momento em que se trata de uma "centralidade da cultura”, no que diz respeito à constituição da experiência humana, assim como das relações sociais que a envolvem. Desta forma, a cultura prolifera-se nas esferas públicas e privadas da vida. Como assinala Hall (1997), um dos principais teóricos dos Estudos Culturais, a cultura

(...) não pode mais ser estudada como uma variável sem importância, secundária ou dependente em relação ao que faz o mundo mover-se; tem de ser vista como algo fundamental, constitutivo, determinando tanto a forma como o caráter deste movimento, bem como sua vida interior (p. 23).

Um dos primeiros efeitos dessa compreensão diz respeito a não se operar com a divisão entre uma cultura popular e uma cultura de elite, devido ao fato de cultura trazer em si a idéia de organização e possibilidades de criação, seja em que tempo-espaço for. Além disso, situa-se que cultura deveria ser compreendida segundo o contexto histórico, político e econômico do qual emerge, ao mesmo tempo em que o constitui. Isso produz um segundo efeito: o de não separar o cenário histórico, político e econômico da produção cultural.

Nas palavras de Hall (1986), a cultura significa "o terreno real, sólido, das práticas, representações, línguas e costumes de qualquer sociedade histórica específica”, como também, “as formas contraditórias de 'senso comum' que se enraizaram na vida popular e ajudaram a moldá-la”(p. 26).

A compreensão do contexto histórico, é importante atentar, não diz respeito à descrição e análise de fatos e acontecimentos, e sim de como o campo que produz e modifica fatos e acontecimentos, bem como o campo que possibilita o aparecimento de fatos e acontecimentos. Essas contribuições encaminham o conceito de cultura para um espaço privilegiado de transformação do ser social, bem como a respostas às mudanças sociais.

Para Silva (1999), a idéia de "construção social” tem funcionado como um conceito unificador dos Estudos Culturais. Este campo de estudo nos lembra que os sentidos que o mundo cultural e social estabelece de forma hegemônica, através da interação social, acabam sendo percebidos como naturalizados, mascarando a origem e a complexidade desse processo. Como nas demais disciplinas, esse também é o propósito da Psicologia Social: expor o processo de construção social.

Hall (1980) afirma que dois passos estão envolvidos em uma nova formulação do sentido de cultura, que surge a partir de mudanças paradigmáticas nas ciências sociais e humanas, identificada como "virada cultural”, expressão utilizada pelo próprio autor quando diz que, com a perspectiva de centralidade da cultura, esta passa a ser considerada como constitutiva da vida social e não somente como uma variável dependente. 
O primeiro passo é um movimento em direção a uma definição antropológica de cultura, como prática cultural (conjunto de normas, valores, regras, costumes...), na qual o sujeito produz e reproduz a cultura, mas é tomado como algo ao lado ou fora dela e não como constituído nela.

O segundo vai em direção a uma definição mais histórica de prática cultural, questionando o significado antropológico enquanto universalidade que se instala por meio dos conceitos de formação social, poder cultural, dominação e regulação, resistência e luta, ou seja, cultura passa a ser objetivada como um território de lutas e contestações através do qual se produzem tanto os sentidos quanto os sujeitos que constituem os diferentes grupos sociais.

No processo de construção das identidades, explicita-se a produção das mesmas pela diferença, mostra que discriminação não é o resultado da diferença. A discriminação fixa determinadas significações, enquanto a diferença nos permite legitimar o que somos. Desta forma, o processo de construção das identidades sempre refere-se a um “outro”, ou seja, "eu sou algo a partir daquilo que eu não sou”, ou "eu não sou o que o outro é”. As pessoas constroem suas identidades a partir das diferenças do que "eles e elas não são” e do que “eles e elas não possuem” (Hall, 2000; Silva, 2000).

Enfim, a transformação do significado de cultura - de textos e representações para práticas de significação - tornou possível considerar as produções de sentidos, em correlação a estratégias de poder e, por isso, práticas políticas. Ou seja, as práticas culturais são interpelativas, isto é, nos incitam a ser como dizem que somos, nos tornam governáveis, mas sempre como foi escrito anteriormente, através de jogos de força, de imposição e contestação de sentidos.

\section{A produção de sentidos e o Construcionismo Social}

A partir desse processo, coloca-se em foco a produção de sentido, que se funda a partir do paradigma do Construcionismo Social ${ }^{4}$. O Construcionismo Social, que traz a importância de uma epistemologia que tem a formação discursiva e o processo de significação como principais pressupostos, propõe a constatação de que a representação é da ordem dos sentidos que o sujeito atribui, tanto no seu âmbito consciente quanto não, ao seu contexto social e cultural. Dessa forma, busca-se inquirir o que os sujeitos dizem, pensam e atuam acerca dos sentidos que constituem o mundo e, de modos diversos, o próprio sujeito.

Os discursos, as relações de poder e o contexto histórico na construção das identidades sociais e culturais são considerados fatores essenciais, na medida em que a produção de sentidos consiste em um deslocamento na rede discursiva. A partir da concepção foucaultiana, entende-se discurso como aquilo que fabrica os objetos dos quais fala, incluindo-se aí os sujeitos. Ao mesmo tempo, essas fabricações se dão em um território de lutas por imposição de determinados sentidos e não outros, os quais vão forjar não aquilo que se é, mas aquilo que nos tornamos.

Uma vez que as práticas sociais são históricas e que fazem nascer novas formas de sujeito e de sujeitos de conhe- cimento, a cultura está diretamente relacionada à produção de sujeitos que se constituem no interior da história e que estão, inevitavelmente, presos à ela, como sugere Fischer (2001): "falar de cultura implica falar de um campo muito específico, qual seja, o da produção histórica e social de significações numa determinada formação social” (p. 26), através do qual damos sentidos as nossas vidas e, por conta disso, nos tornamos sujeitos. Apreender o sujeito de forma não essencializada, histórica e culturalmente constituído, implica operar dentro de uma perspectiva em que o sujeito nunca é idêntico a si mesmo por todo o sempre, já que guarda uma abertura para o tempo, um tempo histórico que o vai posicionar na diferença e não no mesmo, através dos tempos. O que se repetiria, neste caso, seria a produção, a potência de diferenciação e não o sujeito.

Os atravessamentos são múltiplos, portanto, não serão somente a escola, a religião, a sexualidade, a raça, a classe social que produzirão sentidos e que, ao mesmo tempo, darão a segurança e a estabilidade de supostos referenciais. A mídia, a ciência, as migrações também ocuparão esses lugares e com a rapidez com que produzem novos sentidos, constituirão permanentemente novas práticas de significação. Ao mesmo tempo em que determinados grupos sociais visam impor permanentemente práticas de significação particulares, os movimentos de contestação também serão permanentes. Como o próprio Foucault (1995) já alertava: “onde há poder, há resistências”, mas essas resistências não são compreendidas como uma grande recusa, mas como pontos que emergem em todo o tecido social.

Aqui entra a perspectiva das Políticas de Identidade, que são tomadas como movimentos de resistências e produtores de novos sentidos, ao não se deixarem inscrever-se em determinadas posições de sujeito e por determinadas posições de sujeito, produzem novas posições, novas práticas de significação.

\section{As Políticas de Identidade e a produção de sentidos}

Da afirmação das diferenças, e portanto das lutas por imposições e negociações de sentidos, nascem as Políticas de Identidade ${ }^{5}$, que surgem em um cenário no qual se tentava impor a cultura como categoria universal, como sistemas de significações que pretendiam expressar o humano e os grupos sociais, segundo categorias universais e naturais préestabelecidas, de acordo com critérios ditos como reais, como materiais, como anteriores a experiência que se faziam deles.

As Políticas de Identidade são organizações de contestação que não se fazem pelo igual, mas pela diferença, não são lutas pela imposição da supremacia de uma identidade, constituem-se justamente na diferença, naquilo que não o são, não em termos materiais, mas em termos discursivos. Dito de outro modo, as Políticas de Identidade mobilizam-se nos espaços de articulação ${ }^{6}$ de sentidos, de práticas de significação, produzidas a partir da composição de determinadas formações discursivas, nas quais os sujeitos são posicionados e se reconhecem como sujeitos, não por aquilo que se identificam, mas por aquilo que identificam como diferença. 
É importante deixar claro que a diferença também não é tomada aqui como categoria universal e natural. A diferença, assim como as identidades, constituem-se em campos discursivos histórico e culturalmente contingentes e, portanto, edificações em determinado tempo-espaço.

Assim, as Políticas de Identidade procuram compreender ações coletivas e individualizadas, bem como a produção de sentidos e, decorrente disso, a construção das identidades como um processo lingüístico, cultural e social, que se dá a partir destas diferenças, travando lutas por imposição de sentidos. Procuram também compreender a complexidade da produção dos estatutos identitários e, por conta disso, dos processos de subjetivação.

Na Psicologia Social, a concepção de Políticas de Identidade, como efeito dos novos movimento sociais, vem contribuir no sentido de que se modifique a noção de identidade como algo que está posto, imutável, fixo. Desta forma, a construção das identidades se processam através de diferentes atravessamentos, o que implica dizer que as identidades são históricas, fluidas e não fixas. Dessa forma, diferentes sentidos são produzidos em diferentes momentos e contextos, e podem ser entendidos como formas de resistência e/ou tentativas de transformação de práticas hegemônicas.

As Políticas de Identidade abordam uma perspectiva importante principalmente em relação à compreensão da produção de novos sentidos, a partir das interpelações discursivas. Aqui também as questões teóricas sobre discurso têm uma dimensão importante para a compreensão dos grupos sociais e suas intersecções na construção de identidades como modos de resistência à imposição de determinados sentidos cultural e socialmente produzidos. Essa construção se dá em espaços como o da escola, da família e de outras instituições, considerados como locais que fabricam identidades constituídas pela relação discursos/materialidades das experiências de vida.

São produzidas no interior de práticas de significação, por isso adquirem uma materialidade discursiva real, tornamse o real nos espaços de articulação, de hibridização de sentidos em que está em jogo uma multiplicidade de categorias referenciais que se fazem a todo o momento, marcando, instituindo e constituindo novas formas dos grupos sociais definirem a si próprios e serem definidos pelos outros. Não se trata, portanto, de um processo dialético em que dois termos originais e antagônicos são combinados e sintetizados em um terceiro termo. Pelo contrário, referimos que os espaços de articulação, de hibridização envolvem uma polifonia de sentidos que são produzidos cotidianamente e que implicam não no fortalecimento de uma ou outra identidade, mas na desestabilização contínua dos marcadores identitários, pela produção contínua da diferença.

Todas as questões acima discutidas se intercruzam para compreender a construção das identidades desses jovens da periferia; neste artigo, especificamente, estas questões estão relacionadas à pobreza, à violência e ao trabalho.

\section{A pesquisa: algumas notas metodológicas}

\section{Contexto da Pesquisa}

A partir de conversas realizadas com professoras e moradores da comunidade, bem como de observações feitas no local onde se realizou a pesquisa, foi sendo possível conhecer e caracterizar o contexto em que esta foi realizada e onde vivem os participantes da mesma.

A escola na qual as entrevistas e discussões de grupo foram realizadas é caracterizada por ter a participação da comunidade, já que programas escolares, pedagógicos e administrativos, bem como a realização de festas na comunidade são discutidas e decididas junto à população da vila. Através do número decrescente de séries podemos perceber a questão sobre o fracasso e a evasão escolar. A escola inicia com nove turmas de primeiras séries e chega a oitava série com apenas uma turma. A maioria dos e das alunas entre a quinta e oitava série situa-se numa faixa etária entre 15 e 18 anos, época em que acontecem o maior número de reprovações e evasões. A maioria dos participantes desta pesquisa possui pelo menos uma reprovação.

Considerando os modos de vida na e da favela, procuramos entender os sentidos produzidos nesse contexto, que os interpelam a construção das identidades nos espaços que habitam, na comunidade e fora dela, onde desenvolvem lutas ininterruptas para não se tornarem marginais. Ao mesmo tempo, estratégias emergem no sentido de tornar ou não a vida diferente quando, por exemplo, os discursos valorizam o fato de estar na escola e ser trabalhador como o oposto de ser um malandro, um traficante ou marginal, que fica nas ruas todo o tempo.

Para estudar os múltiplos atravessamentos que fazem parte do processo de construção das identidades é necessário lançar o olhar para além desta realidade, ou seja, para compreender outras culturas é necessário, não apenas escutar e observar, mas principalmente ir a espaços que não são dominados por discursos acadêmicos. Assim, uma das características das pesquisas situadas no campo dos Estudos Culturais é o abandono de posturas etnocêntricas e a compreensão de tudo em seu contexto. Os contextos existem como campos de cultura que produzem significados específicos para aqueles que os criam, transformam e neles vivem. A comunidade que descreveremos representa um destes contextos. Seu complexo contexto social está cercado por estruturas geográficas específicas, práticas históricas e culturais, e problemas econômicos e políticos.

A comunidade pesquisada começou a ser formada em meados da década de 70 e, como a maioria das vilas de Porto Alegre, é um resultado do êxodo rural. Em função das situações precárias nas quais as pessoas chegaram da zona rural à favela, os espaços que tiveram para estabelecer suas casas eram pequenos e em geral essas foram construídas com materiais frágeis, tornando-se moradias bastante precárias. Embora a procura por trabalho e a busca por uma vida melhor fossem as razões principais pelas quais as famílias dos estudantes deixaram a zona rural, outros motivos também determinaram o movimento de suas famílias das áreas rurais para as favelas. 
Assim, os sentidos de viver em uma favela podem ser compreendidos, algumas vezes, como viver excluído na sociedade e não considerar a si mesmo um cidadão. É considerado o oposto de viver em edifícios, casas boas, e bairros "limpos”. Assim, ser um favelado pode ter um significado negativo e pejorativo que indica morar em lugares sujos, em que faltam estruturas físicas e materiais, e não possuir qualificações especiais para o trabalho, ou mesmo uma boa aparência pessoal. Nesse sentido, este estudo visa problematizar os hibridismos, ou seja, a multiplicidade de intercruzamentos, produzidos em torno das fixações das identidades e diferenças, em que um dos modos de vida é privilegiado e o outro não.

\section{Participantes}

Participaram dessa pesquisa 16 jovens, sendo 8 meninas e 8 meninos, entre 15 e 18 anos, que nasceram e sempre viveram nesta comunidade, com exceção de um dos meninos. Os alunos freqüentam a escola pelo turno da manhã sendo que as meninas geralmente permanecem em casa pelo turno da tarde fazendo trabalhos domésticos ou tomando conta de irmãos. Os meninos, por sua vez, auxiliam na renda familiar executando algum tipo de trabalho ou ficam pela rua jogando bola ou conversando com amigos. A maioria deles reside com as mães e irmãos e, em alguns casos, com avós e os pais.

\section{Método de pesquisa e de análise}

Foram realizados 16 entrevistas individuais e 6 grupos de discussão, entre os quais 2 grupos mistos da $8^{\underline{a}}$ série e 2 da $5^{\underline{a}}$ série, um grupo somente com meninas e outro somente com meninos. Os grupos foram semanais e tiveram duração aproximada de 1 hora e 30 minutos, durante um período livre, entre as aulas. Os grupos iniciavam discutindo seu dia-a-dia na escola e, quando este assunto parecia esgotar-se eram colocadas questões sobre o cotidiano de sua vida na favela. Procurou-se explorar todas as formas de interações sociais que os alunos estabeleciam na comunidade. Nas entrevistas procurou-se aprofundar questões específicas que surgiram nos grupos no que dizia respeito aos aspectos de gênero, raça, sexualidade, classe social, violência, pobreza, trabalho, lazer, nas interações nos espaços da casa, da rua e da escola. Essas entrevistas não tinham um roteiro prévio estruturado, porém, as perguntas estavam relacionadas a questões do seu cotidiano e de como é viver nesta comunidade.

O processo de análise dentro do Construcionismo Social se propõe a compreender os sentidos produzidos pelos sujeitos. Em nossa pesquisa, procuramos entender como são estabelecidas as práticas discursivas que emergem da produção dos sentidos de jovens em seu cotidiano, oportunizando, a partir disso, a construção de um novo conhecimento.

Assim, após a transcrição dos grupos e das entrevistas, em um primeiro momento, procuramos “deixar aflorar os sentidos, sem encapsular os dados em categorias, classificações ou tematizações definidas a priori” (Spink \& Frezza, 1999, p. 106). Em seguida, foram elaborados quadros/mapas para análise, de maneira a propiciar a visualização dos sentidos. Neste artigo, discutiremos as temáticas que emergiram acerca de questões relacionadas à pobreza, à violência e ao trabalho.

\section{Pobreza, violência e trabalho: produção de sentidos de meninos e meninas}

Ao longo das discussões realizadas nessa pesquisa, surgiu uma série de questões importantes quanto aos sentidos produzidos a partir de suas interações sociais frente à pobreza, à violência e ao trabalho.

A pobreza e o sofrimento são tomados como fatores que constituem a favela, a partir dos quais as pessoas desenvolvem valores sociais e morais, pois o modo como os experimentam $^{7}$, apresenta-se de diferentes formas, de acordo com a posição que ocupam em relação aos discursos da pobreza e do sofrimento. Através disso, definem e classificam não só a si mesmos, mas também às pessoas da vizinhança ou que moram fora da favela.

A pobreza é identificada através da estrutura e material das casas e nas roupas das pessoas; "as pessoas que moram aqui não têm casas bonitas ou roupas boas; seus refrigeradores estão sempre vazios e à noite passam frio e não conseguem dormir”. Os moradores da favela são objetivados como pessoas sem educação, pobremente vestidas e que falam incorretamente. Desse modo, os discursos são semelhantes ao que a autora Carolina de Jesus (1960) afirma: “os pobres sempre estão necessitando, uma vez que nunca descansam (...) suas crianças estão sempre famintas (...) e sempre sujas” (p. 14, 31 e 97). Tais características são tidas como critério, a partir do qual as pessoas das camadas média e alta identificam aqueles que moram na favela. Assim, em contraste com a pobreza da favela, dizem que estas pessoas de camadas mais elevadas se vestem bem, são educadas, têm uma boa aparência e falam diferentemente. Em outros momentos se pensam como diferentes dos outros moradores da favela que ficam em suas casas pelo medo que sentem de ser assaltados e raptados por outros moradores, identificados como bandidos e ladrões.

Diferentes sentidos são produzidos sobre as razões que fazem com que as pessoas na favela, principalmente os jovens, tornem-se marginais, traficantes, ladrões e violentos. A estrutura familiar e a "ausência" do cuidado e controle de suas mães são tidos como fatores que podem levar as crianças a se envolverem com as drogas e com traficantes, o que se caracteriza como um modo de sobrevivência para a maioria das pessoas na comunidade, além de fazer com que se tornem violentas:

existem pessoas que arrumam confusão e outras que são bem educadas. Tem um cara perto da minha casa que é traficante e agora está tentando 'pegar' crianças para fazer isso para ele, como um garoto de 14 anos que mora na frente da minha casa. Ele não é mais ‘informado' porque sua mãe nunca está por perto para dizer para ele que não deve fazer coisas como esta. Esta é uma grande razão pela qual muitas crianças se envolvem em coisas que não deveriam, porque suas mães não estão por perto. 
Essa enunciação toma a relação mãe e filho como fundamentais na constituição das identidades desses adolescentes. Silva (2000) afirma que a identidade e a diferença não podem ser compreendidas, nem separadamente nem fora dos sistemas de significação nos quais adquirem sentidos, o que nos possibilita um entendimento destas questões dentro de um contexto particular, de um campo de utilização.

O uso de drogas possui vários sentidos, pode servir como um meio para aliviar a dor e a fome ou um modo de se ganhar dinheiro. Além disso, muitas vezes, as pessoas justificam o uso de drogas pelos fatores econômicos e sociais que fazem parte do lugar onde vivem.

Os discursos objetivam os traficantes; de um lado como pessoas "boas”, “educadas” e “simpáticas”, já que muitas vezes ajudam os moradores da favela com dinheiro, compram refrigerantes, presentes e doces para as crianças. Por outro lado, a amizade entre habitantes da favela e bandidos faz com que as pessoas que lá residem tenham medo de fazer alguma coisa contra os marginais, fazendo com que, em geral, eles tenham uma posição silenciosa e passiva em relação à violência. Essas relações sociais estão sujeitas a vetores de força, ou seja, a relações de poder, que não são simplesmente definidas, mas impostas. Nesse caso, a droga e o traficante assumem diferentes sentidos, de acordo com o campo de utilização no qual se encontram.

Os traficantes são acusados, muitas vezes, de envolver as crianças e adolescentes no tráfico de drogas, fazendo deles parte de gangues, levando-os a largar a escola e a família e transformando-os em marginais ou iniciando-os no "mundo do crime”. Esta situação faz com que os bandidos ameacem matar membros da família das crianças e adolescentes caso não se submetam às regras da gangue. Às vezes isto faz com que estas famílias tenham de se mudar de vila por causa do medo e das situações perigosas pelas quais passam. Ao mesmo tempo, o traficante e a droga são experimentados como meios através dos quais a vila pode mudar de qualidade de vida, no que diz respeito à autonomia, à autogestão, à proteção, à justiça, ao alívio da dor e da fome.

Relatam que, apesar das pessoas de níveis mais elevados da sociedade verem a favela como perigosa, elas vão lá para comprar drogas. Além disso, ainda em relação às drogas, referem que, às vezes, são confundidos com jovens que participam de gangues ou com parentes que estão envolvidos no tráfico de drogas:

Eles pensam que todas as pessoas que moram na vila são ladrões ou marginais. No meu trabalho, quando contei para eles que eu morava na vila, eles ficaram um pouco com 'o pé atrás'. Às vezes eles dizem isso para mim, mas dizem que estão só brincando, mas é realmente assim que eles pensam.

Compreendemos que essas significações são produzidas por hibridismo, referindo-nos à multiplicidade que é fruto da migração de um espaço ao outro, o que implica a desestabilização das identidades de acordo com um princípio de diferença. Entretanto, com o cruzamento de fronteiras os sistemas classificatórios, que procuram identificar identidades, estão constantemente modificando-se.
Generalizam a questão da criminalidade, tomando-os como assaltantes, bandidos e traficantes, quando afirmam que pessoas más e violentas existem em qualquer lugar, ou seja, o fato de morarem na favela não serve como critério para classificá-las como tal, resistem a sentidos hegemônicos.

A violência é tida como algo natural. Se, por um lado é tomada como algo passado, que aconteceu somente há alguns anos, quando a vila começou a ser formada, por outro é estranhada e tida como agravada, como uma conseqüência das más condições de vida das pessoas de hoje em dia. O espaço da vila onde moram não é tido como violento. Assim, a violência é localizada em outras vilas perto de sua comunidade, nas ruas da favela, deslocando, muitas vezes, a violência para outros lugares, que não o lugar onde vivem: "a rua de baixo é uma rua boa, tem muitos trabalhadores e todo mundo é educado. Mas aqui em cima tem uma rua horrível. Têm muitos traficantes e eles estão sempre brigando com armas e isso é muito ruim.”

Assim, os atos violentos, como estupros, roubos, assaltos, tráfico de drogas, luta de gangues e mortes, geralmente acontecem fora de sua vila. Isso reflete a tentativa de preservar a imagem do lugar onde vivem, distinguindo eles mesmos e aqueles que não moram na área. Alguns estudantes acusam as notícias da estação de rádio local e as dos jornais de transmitirem para as pessoas das camadas médias e altas da sociedade, a idéia de que os habitantes da vila são todos perigosos e que a violência somente existe nela.

Os problemas com violência também fazem com que as pessoas evitem sair da vila durante o fim de semana inteiro, preferindo ficar em casa assistindo à televisão, ao invés de irem a bares e clubes que são freqüentados por bandidos e traficantes de droga. Além disso, a noite na vila é considerada ainda mais violenta, pois é quando ocorrem brigas entre as gangues, traficantes e policiais.

A mídia e a polícia enunciam discursos que objetivam todos os habitantes da favela como bandidos em potencial, como dito anteriormente; existe uma luta por imposição de outros sentidos que não esse sobre as pessoas da favela. Não obstante, a pobreza é tomada como razão que, muitas vezes, leva as pessoas a roubar, traficar ou mendigar, pois esta é uma forma mais fácil de ganhar dinheiro quando não se tem trabalho. Dessa forma, são interpelados por outros discursos acerca da pobreza aos quais resistem em diversos momentos, tendo como correlato o discurso da bandidagem, ou seja, de que a pobreza enuncia bandidagem. Por conta disso, a segurança pública administrada pela polícia não é bem vista, já que a maioria das pessoas da favela classifica os policiais como inimigos, sendo caracterizados como mais violentos e corruptos do que os próprios bandidos, pois muitos se envolvem com roubos e tráfico de drogas.

A visão é de que os policiais agem de um modo discriminatório e arbitrário com os habitantes da favela, invadem suas casas e, muitas vezes, tratam as pessoas com extrema brutalidade:

Há sempre uma coisa nova acontecendo aqui. No outro dia fui comprar remédios para meu irmão e a polícia estava na rua. 
Eles mexeram comigo, cheiraram o remédio para ver se era droga, me chutaram na perna e me disseram para ir embora. Mas isto não é tão ruim. Pior ainda foi ano passado quando a polícia atirou num guri.

Assim, a vida diária na favela é rodeada por um clima tanto de violência quanto de segurança, visto que a vila é um espaço em que as pessoas podem esconder-se do que é considerado como perigo e que também está fora da vila.

O discurso do trabalho tem como correlato o da pobreza, já que aqueles que são definidos como pobres são em geral identificados como "trabalhadores", visto que impõe-se social e culturalmente uma divisão entre trabalho braçal e trabalho intelectual, considerando este último relacionalmente àqueles que têm acesso à escola e, por conta disso, à possibilidade de formação e de especialização. Existe também uma distinção entre serviço, que é considerado apenas uma execução de tarefas, sem vínculo empregatício; emprego, ou seja, o trabalho em órgão público ou empresa estatal; e o trabalho propriamente dito, que implica uma estabilidade, realizado em empresa privada. Aqueles que têm um serviço ou um emprego são considerados como "trabalhadores" e diferenciam-se dos indigentes, vagais, bandidos e marginais.

O trabalho é tomado como critério pelas pessoas de fora da favela para identificar e caracterizar as pessoas que moram nela, ou seja, o trabalho indicará para as pessoas de fora da favela se podem ou não confiar em quem mora nela. Por outro lado, o trabalho é visto como algo que pode afastar as crianças e os jovens da escola. Isto ocorre porque eles precisam contribuir na renda familiar, além de terem que auxiliar nas tarefas domésticas. Esta situação faz com que alguns jovens se sintam desmotivados quando percebem a pequena probabilidade de mudar suas condições de vida ou quando notam que suas vidas não são comparáveis com as dos jovens de camadas médias. Porém, alguns estudantes demonstram pouco interesse em estudar e se preocupam mais com a possibilidade de achar um trabalho que possa lhes dar dinheiro para comprar roupas, sapatos, equipamento de áudio, CDs, fitas, ou para sair para dançar e beber. Ao mesmo tempo que tomam os valores produzidos nas relações com a comunidade em que vivem como verdadeiros, ou seja, pela contingência que cria a necessidade de irem para a escola para conseguirem um trabalho melhor, são interpelados por discursos da mídia que legitimam o modo como o adolescente fala e é falado, por exemplo, comprar CDs, roupas, tênis etc.

Na maioria das famílias dos estudantes dessa pesquisa, as mães são solteiras ou separadas e, assim, o pai é geralmente uma figura passageira. Isso faz com que, para auxiliar na renda familiar, se produza a necessidade dos meninos em trabalhar fora de casa, ainda muito jovens, em atividades como cuidar de carros nos estacionamentos, como officeboys em uma empresa, fazer compras ou pagar as contas para suas mães.

Já as meninas, em sua maioria, não saem para trabalhar fora e suas tarefas cotidianas são, por exemplo, limpar a casa, lavar os pratos e cuidar dos irmãos mais novos, sendo que algumas referem também a prática de esporte como fazendo parte de suas atividades diárias. Nos finais de semana, as meninas dividem seu tempo entre ajudar suas mães em casa, fazendo tarefas e ter um pouco de lazer na comunidade, fora da vila, em casa ou na casa de amigos. Este aspecto denota uma divisão entre o espaço privado, mais reservado às mulheres e o espaço público, mais destinado aos homens. Essa articulação demonstra, por um lado, a naturalização de um discurso hegemônico, à medida em que as meninas são destinadas ao serviço doméstico e os meninos ao trabalho fora de casa e, por outro, a construção de um novo sentido, no momento em que a mãe deixa o espaço da casa para buscar trabalho, passando a fazer parte da esfera pública.

Nesse sentido, as mulheres, nos finais de semana, são as únicas que consideram a família e a casa como parte de seu lazer real e de seu tempo, usando seu tempo "livre” para fazer tudo que é necessário em casa, e que elas não podem fazer durante a semana por causa do trabalho. Nos finais de semana elas cozinham, lavam roupas, limpam, consertam e pintam as casas, fazem compras etc, diferentemente dos homens, que estão sem obrigações e aproveitam o tempo para jogar futebol e estar nas ruas ou em bares. São relações sociais e, portanto, lutas por imposições de sentidos no momento em que acontecimentos como, por exemplo, a mulher passar da esfera privada para pública, modificam o modo como estes estudantes experimentam as práticas discursivas no que diz respeito às relações entre gênero e trabalho.

\section{A luta pela imposição de sentidos no cotidiano}

Ao mesmo tempo em que lutam contra imagens discriminatórias das pessoas de fora da favela, também produzem outros sentidos, já que criam uma imagem, dividindo os habitantes da favela entre "trabalhadores" e marginais, honestos e bandidos, calmos e violentos. Ou ainda, produzem diferentes entendimentos sobre as razões que fazem com que as pessoas na favela, principalmente os jovens, tornemse marginais, traficantes e ladrões. Evidencia-se, assim, uma identificação com discursos hegemônicos de que, por exemplo, “quem vive na favela é ladrão, traficante etc.”. Ao se apropriarem de determinados discursos e não de outros, os tomam como verdades e produzem resistência em relação a eles dentro do próprio campo de utilização, quando afirmam que "nem todo mundo que vive na vila é ladrão...", objetivando de outro modo estes discursos.

Enquanto o espaço doméstico é designado para o serviço doméstico das meninas, é exigido dos meninos que façam suas atividades no espaço público. A respeito desta divisão de trabalho entre os meninos e meninas é interessante notar que há diversos discursos que os interpelam na construção de suas identidades, a intersecção de aspectos que dizem respeito às relações de gênero e à idade. Para evitar o perigo das ruas, suas mães querem os meninos em casa como também as meninas, ao mesmo tempo em que os meninos precisam trabalhar para ajudar na renda familiar.

A necessidade de trabalhar cedo, porque a maioria dos pais está trabalhando no mercado de trabalho informal, ganhando salários mensais que forçam alguns estudantes a largar a escola e por conseguinte, diminuir as perspectivas para 
uma melhor posição em suas vidas, que eles entendem ser possível pelo estudo e pelo trabalho. Assim, o trabalho e o estudo são significados como a possibilidade de mudar de vida, relacionando o lazer com atividades ocasionais.

A “saída” para a violência e o tráfico de drogas na periferia, é tomada, em determinados contextos e momentos como sendo algo não totalmente nocivo ou ruim, visto que esse "trabalho" traz, por um lado, o aumento da violência e do envolvimento com a polícia, mas por outro, acaba por auxiliar na renda das pessoas que lá residem. Assim, em certos momentos apropriam-se de certos discursos e não de outros quando emitem algum juízo de valor, tomando alguns sentidos como verdades e outros não.

Uma série de tentativas que buscam oportunidades para mudarem de vida são produzidas. Dessa forma, ao mesmo tempo em que objetivam diferenças entre morar em uma favela e em um bairro de classe média, também querem distinguir eles mesmos daquilo que não é considerado como promissor. A idéia de favela como um lugar indesejável é tomada como verdade por eles quando descrevem os valores culturais das pessoas que vivem em lugares mais prósperos.

Nesse cenário, as identidades dos estudantes são construídas a partir da apropriação de determinados discursos, através dos quais atribuem novos sentidos e possibilidades de transformações que implicam práticas políticas, entendidas aqui como as lutas em uma sociedade pela imposição de sentidos.

Enunciam os conflitos que são experimentados no seu dia a dia na favela - ao mesmo tempo em que, em alguns momentos, lutam contra imagens discriminatórias das pessoas de fora, em outros, se apropriam de sentidos que dividem os habitantes da favela entre "trabalhadores" e marginais, honestos e bandidos, calmos e violentos.

Esses binarismos são construídos no tecido social e são tomados como verdades por eles, não são naturais, mas emergem e adquirem sentido quando esses se posicionam na rede discursiva enunciando os efeitos dessas práticas discursivas, pois forjam identidades, forjam os modos deles serem e se pensarem.

O que tentamos mostrar com este estudo é o papel das Políticas de Identidade nas emergências de novas práticas discursivas, que produzem novas identidades e, por conta disso, diferentes modos de os adolescentes se pensarem e pensarem o mundo em que vivem. Assim, travam lutas por imposição de outros sentidos que os atravessam, des- naturalizando as identidades culturais ao desestabilizá-las nos e pelos movimentos de migração e cruzamento de fronteiras.

\section{Referências}

Escosteguy, A. C. (2000) Estudos Culturais: uma introdução. In T. T. Silva (Org.), O que é, afinal, Estudos Culturais? (pp. 133-166). Belo Horizonte: Autêntica.

Fischer, R. M. (2001). Televisão \& Educação: fruir e pensar a TV. Belo Horizonte: Autêntica.

Foucault, M. (1995) O sujeito e o poder. In H. Dreyfus \& P. Rabinow (Orgs.), Michel Foucault - uma trajetória filosófica: para além do estruturalismo e da hermenêutica (p. 131-149). Rio de Janeiro: Forense.

Guareschi, N. (1999). Políticas de Identidade: uma breve concepção. Revista Educação (Ed. Especial), XXII(39), 7-26.

Guareschi, N. (2000, jan./dez.). Políticas de Identidade: novos enfoques e novos desafios para a Psicologia Social. Psicologia e Sociedade, 12(1/2), 110-124.

Guareschi, N., \& Bruschi, M. (2003). Psicologia Social nos Estudos Culturais. Petrópolis: Vozes.

Hall, S. (1980). Cultural Studies and the Centre: some problematics and problems. In S. Hall, D. Hobson, A. Lowe \& P. Willis (Orgs.), Culture, media, language - working papers in cultural studies (pp. 1972-1979). Londres: Routledge \& Centre for Contemporary Cultural Studies/University of Birmingham.

Hall, S. (1986). Gramsci's relevance for the study of race and ethnicity. Journal of Communication Inquiry, 10(2), 5-27.

Hall, S. (1990). Cultural identity and diaspora. In R. Jonathan (Org.), Identity: community, culture, difference (pp. 222-237). Londres: Lawrence \& Wishart.

Hall, S. (1996). Cultural studies and the politics of internationalization: an interview with Stuart Hall by Kuan-Hsing Chen. In D. Morley \& K. Chen (Orgs.), Stuart Hall - Critical Dialogues in Cultural Studies (pp. 392-408). Londres/Nova York: Routledge.

Hall, S. (1997, jul./dez.). A centralidade da cultura: notas sobre as revoluções de nosso tempo. Educação e Realidade (Porto Alegre: UFRGS), 22(2), 15-46.

Hall, S. (2000). Quem precisa da identidade? In T. T. Silva (Org.), Identidade e diferença (pp. 103-133). Petrópolis: Vozes.

Jesus, C. M. (1960). Quarto de desejo. São Paulo: Francisco Alves.

Johnson, R. (1986). The story so far: and further transformations. In D. Punter (Org.), Introduction to contemporary cultural studies (pp. 277-313). Londres: Longman.

Nelson, C., Treichler, P. \& Grossberg, L. (1995). Estudos Culturais: uma introdução. In T. T. Silva (Org.), Alienígenas na sala de aula (pp. 7-38). Petrópolis: Vozes.

Silva, T. T. (1999). Documentos de identidade: uma introdução às teorias do currículo (2a ed.). Belo Horizonte: Autêntica.

Silva, T. T. (Org.). (2000). Identidade e diferença. Petrópolis: Vozes.

Spink, M. J. \& Frezza, R. M. (1999). Práticas discursivas e produção de sentidos: a perspectiva da Psicologia Social. In M. J. Spink (Org.), Práticas discursivas e produção de sentidos no cotidiano: aproximações teóricas e metodológicas (pp. 17-41). São Paulo: Cortez.

\section{Nota}

1 Agradecimentos às instituições que financiaram este projeto: FAPERGS, PIBIC/CNPq e BPA/PUCRS

2 Maiores informações sobre o campo do conhecimento dos Estudos Culturais e seus enfoques teóricos e metodológicos podem ser encontrados nos seguintes trabalhos: Escosteguy, 2000; Guareschi \& Bruschi, 2003; Hall, 1980, 1990; Johnson, 1986; Nelson, 1995.

3 O referencial da Produção de Sentidos se funda a partir do paradigma do Construcionismo Social, embora seja igualmente utilizado por outras perspectivas. 
4 A perspectiva teórica do Construcionismo Social pode ser considerada como resultante de três movimentos: na Filosofia, como reação ao representacionismo; na sociologia do conhecimento, como uma desconstrução da retórica da verdade; e na Política, como busca, através da educação de grupos sociais ditos subordinados, de adquirirem meios de fortalecimento para fazer frente aos discursos hegemônicos (Spink \& Frezza, 1999).

5 Discussões acerca do tema das Políticas de Identidades são realizadas em obras de Guareschi (1999, 2000).

6 Para Hall (1996), a teoria da articulação "é a forma de conexão que pode fazer uma unidade de dois elementos diferentes, sob certas condições. É uma ligação que não é necessária, determinada, absoluta e essencial para todos os tempos. A assim chamada 'unidade' de um discurso é na realidade a articulação de elementos diferentes, distintos que podem ser articulados de modos diferentes porque não têm necessária pertença” (p.115).

7 Por experimentação entende-se a correlação entre campos de saber, relações de poder e formas de subjetivação.

Neuza Maria de Fátima Guareschi é Professora Doutora, Orientadora do Grupo de Pesquisa "Estudos Culturais, Identidades/Diferenças e Teorias Contemporâneas” do Programa de Pós-Graduação da Faculdade de Psicologia da Pontifícia Universidade Católica do Rio Grande do Sul.

Fernanda Pacheco de Oliveira, Letícia Goldenberg Giannechini, Luciele Nardi Comunello, Milena Nardini e Milena Leal Pacheco são bolsistas de pesquisa do Grupo 'Estudos Culturais, Identidades/Diferenças e Teorias Contemporâneas’ do Programa de Pós-Graduação da Faculdade de Psicologia da Pontifícia Universidade Católica do Rio Grande do Sul.

Endereço para correspondência: Faculdade de Psicologia/Programa de Pós-Graduação Prédio 11 (9ํandar) Pontifícia Universidade Católica do Rio Grande do Sul - Campus Central. Av. Ipiranga, 6681 - CEP 90619900 - Porto Alegre, RS - Brasil. Fone: (51) 3320-3500 - Fax: (51) 3339-1564. E-mail: nmguares@pucrs.br 